\title{
Design Programs at the Simon Fraser University School of Interactive Arts and Technology
}

\author{
R. Woodbury, J. Budd, J. Bowes, J. Fee \\ School of Interactive Arts and Technology \\ Simon Fraser University \\ rw@sfu.ca, jbudd@sfu.ca, jbowes@sfu.ca, ifee@sfu.ca
}

\begin{abstract}
The School of Interactive Arts and Technology (SIAT) was created when The Technical University of British Columbia was merged with Simon Fraser University. The school hosts undergraduate and graduate programs in design, art and technology with current enrolment of 800 undergraduate and 85 graduate students. SIAT is unique in Canadian higher education and has few comparators world-wide. This paper presents the motivation for SIAT's undergraduate and graduate programs, their structure and posits consequent questions for design education.
\end{abstract}

\section{Author Keywords}

Design education, interaction design, human-centred systems, interdisciplinary.

\section{OVERVIEW}

There can be little doubt that design is in demand. Globalization is pushing developed nations to highvalue added economic strategies. Products, systems and built environments are increasingly complex both of themselves and in the human-system interactions they sustain. People demand sophistication in the systems and products they use. These reasons and many others put a premium on understanding, managing and practicing design. Design - the process of making proposals for change - is both common and core to many disciplines. It should not be surprising to find that design across disciplines has strong commonalities and sharp discipline-dependent distinctions. The new hybrid program in the School of Interactive Arts and Technology aims to teach a common design core of ideas, attitudes and skill together with the specifics required for expertise in particular areas.

For the past five years we have been building the infrastructure of a new school, designed from the outset to educate a new generation of designers to address these challenges. The new program is explicitly interdisciplinary and brings together faculty and students from a range of disciplines bridging art, design and technology. The program has two primary goals. The first is to explore, understand and critically evaluate the interplay between technology and society. The second is to foster the development and design of new technologies to benefit society. There are several key factors that differentiate this program from those of more traditional design schools. In particular, we emphasize the need to balance the technical (utilitarian and performance) with the human (cognitive, social and cultural) parameters throughout the design development process by building an active dialogue with prospective users. In addition the program advocates structured field-testing as an integral part of the methodology to validate the combined goals of function, utility, performance and experience. The dual intentions here are to ensure that designs are appropriate to their receptor communities and to strengthen the relationship between theory and practice.

Another key difference is clearly evident in the unique structure and delivery of the curriculum designed to respond to the demands of the technological change that is radically reshaping our world today.

\section{UNDERGRADUATE PROGRAM}

The School of Interactive Arts and Technology offers a program leading to $\mathrm{BSc}$ and $\mathrm{BA}$ degrees with major or honors in Interactive Arts and Technology. Students seeking the major or honors elect one of four streams: Performance and Media Arts, Interaction Design, New Media Environments and Technology in Art and Design.

All streams in the program share a fundamental concern with people using technology in context. Each draws from distinct patterns of scholarship and thinking - each has its own academic emphasis, which 
leads directly to its particular pattern of study and set of graduate outcomes.

The undergraduate streams each address a societal need for graduates with generic design and media knowledge and skill and knowledge in specific areas. The overall structure of the curriculum addresses the general qualities; the streams aim at specifics.

\section{TechOne: Building a common core}

What is common across design disciplines? This surely is one of the key questions for design education, but the question is itself an insight. A common attribute for designers is the need to work with others (designers and non-designers) who bring expertise needed for part of a design situation. Today there are few design problems for which a single person can hope for mastery. Design is collaborative and designers work in teams. Much (arguably most) design focuses on people using technology, yet it is just this human-system interface that is perhaps the leastunderstood aspect of designed artifacts. Historically, designers have had little formal background in how people work, learn and play. Today design media are digital, and digital media present capabilities that greatly affect (and usually enhance) what designers can do. Designers display a set of attitudes that help them be effective. The beliefs that there is always a solution, that design criticism is never personal, that designs have multiple criteria and that the problem develops with the design that solves it are all welldocumented qualities of successful designers.

Out first year program TechOne has the dual aims of being a supportive introduction to a broad-based university education and providing a foundation for further work in each of the disciplines of its host faculty (Applied Sciences). TechOne is a cohort program - students study with a peer group and the TechOne curriculum trades heavily on developing effective peer relations as an enabler of success at university. TechOne students are guaranteed registration and access to the full TechOne course offering..

The TechOne Program provides students with a strong foundation in technology, communications, art, business and mathematics. TechOne is a natural springboard into the SIAT bachelor degree programs (and also those offered by the School of Computing Science and the Faculty of Business). Students who complete TechOne can also transfer into second-year studies in other Simon Fraser University degree areas.

\section{The TechOne Curriculum}

Much like the pedagogical approach in the studiobased model of a more traditional design program, team-based learning and peer support are important contributors to student success. In addition the new program delivery methods include a combination of lectures, workshops, labs and online learning. Students work individually, in teams (Figure 1) and large groups, in classrooms, computer labs studios and online spaces. Much of the online work is done together with other students in teams - and much of this work is handled outside of regularly scheduled class time. This approach to teaching and learning provides an additional level of flexibility in scheduling for the students. At all times students have excellent access to their instructors.

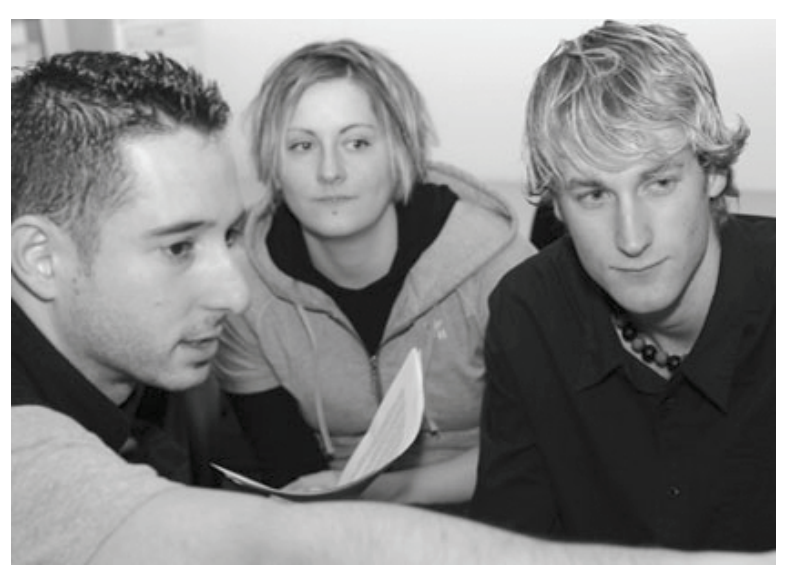

Figure 1: Teamwork is a critical component of the curriculum

The TechOne Curriculum consists of 30 credits of required and elective courses taken over two terms (5 classes per term). TechOne students must register in the six core courses as shown in Table 1 (below). Core course are interdisciplinary: they bring together arts, science, technology and communications in "real world" ways. As part of the common core students learn the principles of effective communication and teamwork; skills and techniques to create digital media; along with the fundamentals of computer programming. 


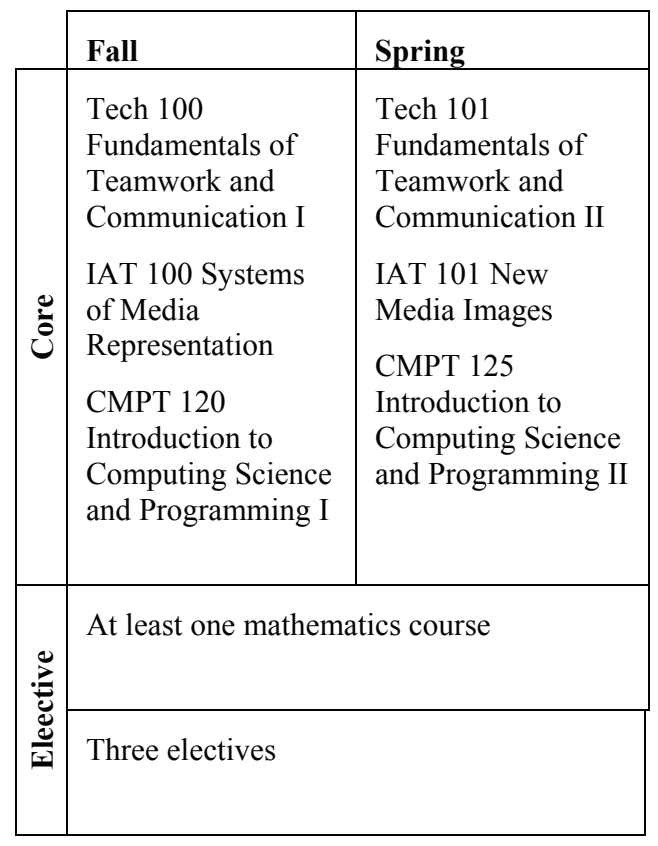

Table 1: TechOne curriculum structure

In addition to these 6 core courses, TechOne students register in at least one course in mathematics (3 credits) plus a minimum of three electives. Students have the flexibility to choose electives related to the stream in which they intend to major or, if a student does not know which stream he or she would like to complete, they may use TechOne as an evaluation year to help them identify areas of interest and make their decision on a specific major following completion of their first year..

The TechOne Program together with the School of Interactive Arts and Technology are only offered at SFU Surrey campus located in the unconventional setting of Central City, a combined shopping mall/office complex (Figure 2).

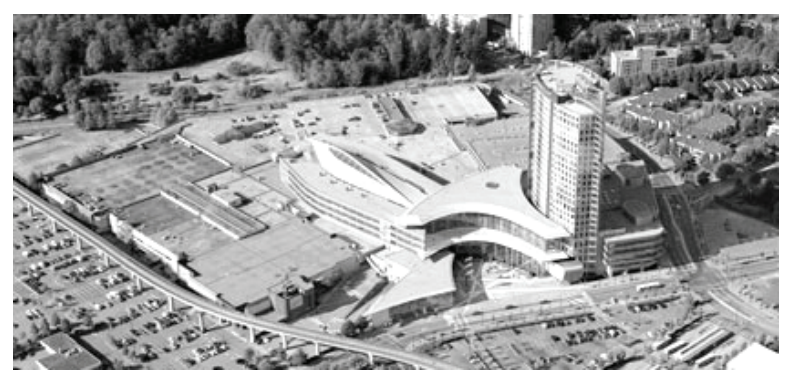

Figure 2: SFU's School of Interactive Arts \& Technology is located in Central City, Surrey, BC.

\section{A Continuum of Four Streams}

Following the completion of TechOne students may elect to enroll in one of the four undergraduate streams. Each of the streams studies design in its own context, for instance, students in Performance and Media Arts (PMA) explore the use of technology in performance and art installation; students in New Media Environments (NME) develop narratives and tools for media (e.g., film, games, publishing, websites) design; students in Interaction Design (ID) focus on user-centred product design; and students in Technology in Art \& Design (TAD) develop humancentred systems (TAD). As shown in Table 2, common curricular elements address the core issues common to all streams.

The streams achieve their ends by a common curricular structure. Each has a set of core courses in both lower and upper division taken by all students in the stream aimed at producing specific graduate outcomes. There is significant sharing of course content among the streams, especially within the electives. Even within the sets of required courses, there is overlap reflecting the fact they are all part of a common program. Work such as that shown in Figure 3 could occur in each of the streams. The common academic threads shared by all four streams include the TechOne foundation year, four lower division SIAT courses and additional common courses for the BA and BSc degrees. Students may earn either the BA or BSc in any of the four streams, though the path to the BA is more clear in the PMA and NME streams, and to the BSc in the ID and TAD streams.

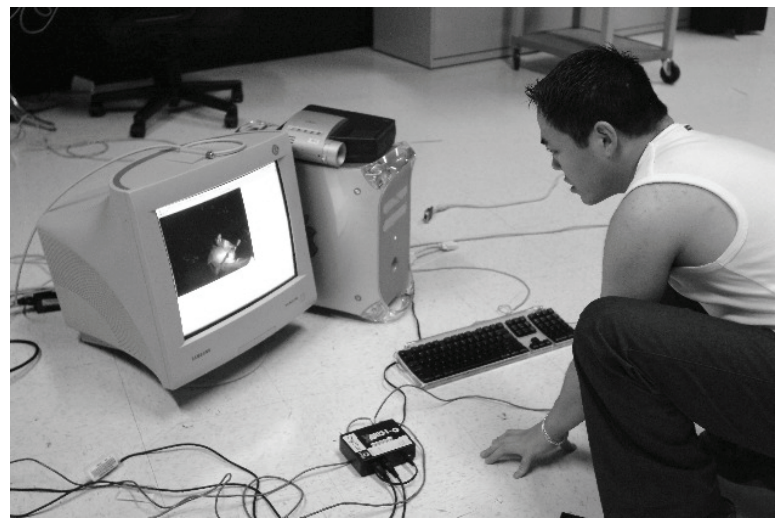

Figure 3: Developing elements of an interactive system. 


\begin{tabular}{|c|c|c|c|}
\hline & Core & Stream & Elective \\
\hline 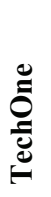 & 6 core courses & & $\begin{array}{l}1 \text { mathematics } \\
\text { course } \\
3 \text { electives }\end{array}$ \\
\hline 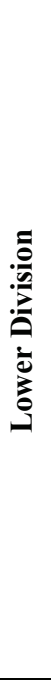 & $\begin{array}{l}\text { TECH } 114 \\
\text { History and } \\
\text { Theory of } \\
\text { Technology and } \\
\text { Culture } \\
\text { IAT } 200 \\
\text { Cognition for } \\
\text { Design Science } \\
\text { IAT } 201 \\
\text { Usability in } \\
\text { Interactive } \\
\text { Environments } \\
\text { IAT/CMPT } 265 \\
\text { Multimedia } \\
\text { Programming } \\
\text { for Art and } \\
\text { Design }\end{array}$ & $\begin{array}{l}5 \text { courses } \\
\text { specific to the } \\
\text { student's } \\
\text { chosen } \\
\text { stream. }\end{array}$ & 1 elective \\
\hline 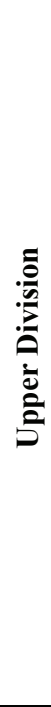 & & $\begin{array}{l}\text { A total of } 10 \\
\text { courses, } \\
\text { including } \\
5 \text { or } 6 \text { stream } \\
\text { core courses. } \\
2 \text { or } 3 \text { stream } \\
\text { project } \\
\text { courses } \\
1 \text { or } 2 \text { stream } \\
\text { elective } \\
\text { courses (all } \\
\text { are core in } \\
\text { other streams) } \\
1 \text { or more } \\
\text { SIAT upper } \\
\text { division } \\
\text { courses }\end{array}$ & 10 courses \\
\hline 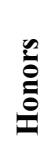 & \multicolumn{3}{|c|}{$\begin{array}{l}\text { IAT } 490 \text { and } 491 \text { Honors Research Project } \\
\text { Additional IAT elective requirements } \\
\text { 3.0 GPA }\end{array}$} \\
\hline
\end{tabular}

Table 2: Undergraduate curriculum structure. All courses earn three credits, except IAT 490 and 491, which earn six credits.

\section{The Four Streams}

Technology in Art and Design (TAD) addresses human-centred system design. It studies technological systems used by people in work, learning and play situations. Its emphasis is on system-building with particular emphasis on how people use systems, how to design and program user-centered systems and how to represent and reason about the objects and environments that people use. Its graduates will be able to make systems that people find useful and engaging.

Interaction Design (ID) examines the relationship between people and technology with the intent to enhance or improve our environment through a reflective design process that incorporates interactive technologies. The fundamental graduate outcomes are a combination of creative action and critical thought that shape the way people make and use highly interactive products, systems and environments.

New Media Environments (NME) is concerned with the creation, analysis and understanding of new media. New media environments are both computational artifacts and cultural experiences. They are therefore highly emergent phenomena that are deeply rooted in historical, social, aesthetic, and economic processes. Graduates of this stream will be skilled in the critical analysis and in the making of new media forms such as electronic games, digital video, computer animation, and interactive multimedia.

Performance and Media Arts (PMA) is based on the artistic interpretation and expression of human experience through interactive technological environments. This stream combines critical theory with artistic practice to produce artworks in the form of installation, performance and exhibition. Its graduates will create new forms of cultural and artistic expression in our technologically mediated society.

\section{GRADUATE PROGRAM}

The SIAT graduate program brings together faculty and students from a variety of disciplines to engage in the study of technology. In so doing, we have several objectives: first, research in technology and its contexts of use, particularly the computational technologies that drive much current innovation; second, development and use of interdisciplinary research methodologies and the development of new technologies; third, research into the acts of inventing, designing, making, managing and learning about technology; and fourth, application of new technologies in society and industry. 
The program is research-based with a dominant thesis or dissertation component. Students are supported by four CFI funded labs with a total capital funding of about 4 million dollars and a graduate student lab funded internally to the program.

A hallmark of the program is its emphasis on interdisciplinarity, team endeavour, combining of concept and practice, and use of technologies as an instructional base. All graduate students take a mandatory course in Research Methods and Strategies, which critically evaluates research philosophies and techniques for collaboration among disciplinary experts. Students learn in an environment that employs traditional coursework, one-on-one mentoring, teamwork, and technology-enhanced learning. In short, students are immersed in an environment that is both technology rich and structured for interdisciplinary cooperation.

The graduate course offerings provide a core of five courses spanning the school's disciplinary facets (information technology, the arts, social science, design and pedagogy). An initial offering of ten electives gives greater depth in specialties such as the sociology of networked communities, methodologies to foster and support user participation in design, spatial computing and technology-mediated games. A hallmark of each is that a traditional disciplinary specialty is eschewed in favour of productive synergies from related disciplines, such as technologies for enhancing theatrical performance.

The program is unique in Canadian higher education. While most universities have depth in computer science, social science, communication, education and the arts, very few host the mix that has been established under the umbrella of the new school. At the same time, such combinations are widely sought by students and regional employers. TechBC's original design was to provide cross-disciplinary scholarship built on regional development needs. This design has been redefined here to reflect the significant advantages afforded by SFU.

\section{Curriculum Structure}

The program offers Master of Arts, Master of Science and $\mathrm{PhD}$ degrees and is structured so that graduates will have the research knowledge and skill required to be effective creators of new knowledge.

The curriculum has six components: (1) Foundations of Computational Art and Design (1 required course), (2) Research Methods and Strategies (1 required course), (3) core courses (2-3 courses of 5 required), (4) elective courses (2-3 courses to be taken), (5) MA Thesis, MSc Thesis or $\mathrm{PhD}$ Dissertation (the $\mathrm{PhD}$ also has a comprehensive examination and dissertation proposal) and (6) Research Colloquium.

In completing a degree, graduates will have developed depth in their chosen research area, breadth in understanding technology in context, ability to work in interdisciplinary teams and scholarly skills for sustained intellectual productivity. These are general qualities of a research degree and each has special significance in the context of the proposed program. Table 1 (below) summarizes the curriculum structure and identifies components corresponding to each of these four main objectives.

Depth of study. The curriculum is dominated by its thesis/dissertation component, which is the primary vehicle for developing depth in a particular topic. To assist students in achieving depth the curriculum has both core and elective courses. The core courses cover areas of broad concern in the program. The elective courses provide in-depth and specialized study. They may be selected from within the program, from other SFU graduate programs or elsewhere. The elective courses particularly are intended to assist students in progressing towards their thesis or dissertation.

Breadth of knowledge. The Foundations of Computational Art and Design course is intended to assure that all students have knowledge of and skill in applying computation appropriate for an advanced degree holder in our disciplinary areas. The Research Methods and Strategies course introduces students not only to the intellectual structure of research but also to the methods available for conducting research across the broad areas with which the program is concerned. The core courses (of which Master's students take two and $\mathrm{PhD}$ students take either two or three) aim to expose students to research issues and results beyond any single topic area.

Interdisciplinarity. The Foundations of Computational Art and Design course draws its examples from a wide range of specialties within the program. The Research Methods and Strategies course has components on interdisciplinary work. In the core courses students work in groups whose members have differing disciplinary foci.

Scholarly skills. The Research Methods and Strategies course has required components on writing scholarly articles, on library research techniques and on scholarly presentation. The core courses require that students meet standards of scholarly production in assessable work. One elective course is required to be a research methods course appropriate to a student's course of study (the particular course is approved by the student's supervisory committee and the graduate 
program committee). The $\mathrm{PhD}$ comprehensive examination has components that test for achievement of scholarly skill sufficient for producing a successful dissertation.

\section{Program Requirements}

The degree requirements minimally are five (5) courses of at least three (3) credits each (nominally 15 credit hours) of coursework for the Master of Arts and Master of Science and six (6) courses of at least three (3) credits each (nominally 18 credit hours) of coursework for the $\mathrm{PhD}$. In addition there is a single course, Foundations of Computational Art and Design, that offers necessary basic concepts and skills for further study in the program and will not count towards the above coursework requirements. All students will be required to take Foundations of Computational Art and Design or demonstrate sufficient knowledge for it to be waived. We anticipate that students with strong technical backgrounds will not need to take this course. Table 3 diagrams the curricular requirements for the program.

$\mathrm{PhD}$ students who have completed a Master's degree within the program will have an option to apply to the program's graduate program committee for a reduction in coursework aimed at breadth and scholarly skill. Such reduction shall not reduce course requirements below those specified in the $\mathrm{PhD}$ (from MA or MSc within the program) option in the table below.

Master's students are admitted to study for either the MA or MSc degree. Students may articulate between the MA and MSc degrees by meeting the admission and program requirements of the degree to which they articulate and with the approval of the Graduate Program Committee. A student may make one application for articulation.

\section{The Degrees}

Students who complete the Master's program are awarded a Master of Arts or Master of Science. The distinction between the two degrees is based on the coursework taken towards the degree. The decision as to degree designation is taken at the time of admission: Master's students will be admitted to either the Master of Arts or Master of Science. Admission to a program will depend upon prior academic preparation and intended focus of study. Students who complete the doctoral program are awarded a $\mathrm{PhD}$.

\section{Requirements for the Degree}

\section{Foundation}

IAT800 Foundations of Computational Art and Design is an introduction to computing as a research and professional tool in art and design. Its intended audience includes those who have not had substantial experience in the computational aspects of art and design. This is a mandatory course for all students in the program, but may be waived for those students having had sufficient formal educational background in art and design computation.

\section{Coursework}

IAT801 Research Methods and Strategies is an introduction to the research enterprise. It covers structures of research that are prevalent across fields, introduces research methodologies and tools, teaches methods for interdisciplinary work and fosters a critical discourse around the fundamental differences among research in different areas. This is a mandatory course for all students in the program.

Core Courses. There are five core courses, each offering the bases for research in an area in which a large group of faculty is involved. These courses have been team-designed and are taught by the faculty in the particular areas. MA and MSc students will be required to take two core courses. PhD students will be required to take either two or three core courses.

IAT810 New Media. This course examines theory, history and current research in the field of new media. Its methods are the interweaving of design, social/cultural, learning and aesthetic theories. Historical views of the field are provided through an analysis of the histories of technology, moments of media emergence, social and cultural movements, design and aesthetics. The outcomes for the course are exploration, analysis and development of applied methods in order to better understand, design, create and assess new media and future "newer media" developments.

IAT811 Computational Poetics. This course provides students the opportunity to engage in critical, creative thinking and practice in the discovery of the emergent overlying principles and concepts that enable one to describe, analyze, evaluate and design interactive multi-mediated experience. The structure of the course centres on art in the age of information, virtuality, compositional design and practice.

IAT812 Cognition, Learning and Collaboration. The aim of this course is to address what it means to know something, how people gain and use knowledge and complex skills, how to determine what an 
individual knows, how humans learn, how humans solve complex problems, how knowledge is created within a social and group context, and how to model human capabilities and performance. We will select and study theoretical perspectives that inform the design of computer-based mediated environments, products and experiences.

\begin{tabular}{|c|c|c|c|}
\hline & & MA and MSc & PhD \\
\hline 总 & $\begin{array}{l}\text { IAT 803-3 } \\
\text { Foundations of } \\
\text { Computational } \\
\text { Art and Design }\end{array}$ & $\begin{array}{l}3 \text { credits } \\
\text { (possibly } \\
\text { waived) }\end{array}$ & $\begin{array}{l}3 \text { credits } \\
\text { (possibly } \\
\text { waived) }\end{array}$ \\
\hline \multirow{6}{*}{ 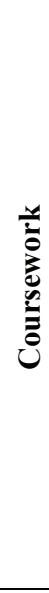 } & $\begin{array}{l}\text { IAT } 801-3 \\
\text { Research } \\
\text { Methods and } \\
\text { Strategies }\end{array}$ & 3 credits & 3 credits \\
\hline & Core & $\begin{array}{l}2 \text { courses } \\
6 \text { credits }\end{array}$ & $\begin{array}{l}2 \text { or } 3 \\
\text { courses* } \\
6 \text { or } 9 \text { credits }\end{array}$ \\
\hline & Electives & \multirow{3}{*}{$\begin{array}{l}2 \text { courses } \\
6 \text { credits }\end{array}$} & \multirow{3}{*}{$\begin{array}{l}2 \text { or } 3 \\
\text { courses* } \\
6 \text { or } 9 \text { credits }\end{array}$} \\
\hline & Special Topics & & \\
\hline & $\begin{array}{l}\text { Directed } \\
\text { Readings }\end{array}$ & & \\
\hline & $\begin{array}{l}\text { Total } \\
\text { Coursework }\end{array}$ & $\begin{array}{l}5 \text { courses } \\
15 \text { credits } \\
\end{array}$ & $\begin{array}{l}6 \text { courses } \\
18 \text { credits } \\
\end{array}$ \\
\hline \multirow{6}{*}{ 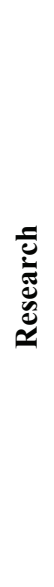 } & $\begin{array}{l}\text { Co-operative } \\
\text { Education }\end{array}$ & Optional & Optional \\
\hline & $\begin{array}{l}\text { Research } \\
\text { Seminar }\end{array}$ & $\begin{array}{l}\text { Attendance } \\
\text { requirement }+ \\
1 \text { presentation }\end{array}$ & $\begin{array}{l}\text { Attendance } \\
\text { requirement }+ \\
2 \\
\text { presentations }\end{array}$ \\
\hline & Master's Thesis & required & \\
\hline & $\begin{array}{l}\mathrm{PhD} \\
\text { Comprehensive } \\
\text { Examination }\end{array}$ & & required \\
\hline & PhD Proposal & & required \\
\hline & $\begin{array}{l}\mathrm{PhD} \\
\text { Dissertation } \S\end{array}$ & & required \\
\hline
\end{tabular}

Table 3: Graduate curriculum structure.

IAT813 Artificial Intelligence in Computational Art and Design. Working through a set of motivating examples from domains such as generative design, dance simulation, social interaction, adaptive user interface design and knowledge sharing in e-learning the course provides insights on how AI techniques can be used to address important problems in art and design. The topics are presented in a comparative manner to clearly highlight advantages and disadvantages of each method providing students with ability to weight benefits of a particular approach when facing a concrete problem in their research area.

IAT814 Knowledge Visualization and Communication. The course provides a cognitive and computational framework for understanding and designing graphical and visual representations. We investigate several psychological and computational models of diagram processing, and explore diverse interactive graphical systems.

\section{Electives}

MA and MSc students are required to take two courses from the pool of electives, special topics and directed readings. $\mathrm{PhD}$ students are required to take either two or three courses from this pool. Subject to Supervisory Committee approval and Graduate Program Committee approval, students in the program may fulfill part of these requirements through other appropriate graduate courses at SFU or elsewhere (the latter subject to SFU rules on external courses). Normally, all students must take at least one course towards these requirements as either an elective or special topics offered within the program. One elective is required to have a focus on research methods appropriate to the student's thesis/dissertation topic. In this interdisciplinary program appropriate research methodologies vary widely. For example, quantitative empirical work requires a background in statistics; process-based social research requires qualitative methods; and computational work may require proofs and formal languages.

Special Topics courses serve several agendas. They provide the needed flexibility to quickly adapt to new contexts and to serve the curiosity-driven inquiry that is essential to our research and graduate program. They serve as incubators for new electives and are the normal way that new elective courses are proposed and refined before they are formally considered for addition to the program. They also provide the program with a means to take best instructional advantage of visiting faculty with skills new to our program.

Directed Readings play the normal function of such courses at SFU. They are seminar or tutorial experiences that develop special research interests in depth and with faculty supervision. Students should not expect to take a directed readings course where there is a substantively comparable course offered at SFU. Directed readings should be distinct from the work to be undertaken towards the MA Thesis, MSc 
Thesis or $\mathrm{PhD}$ Dissertation. Normally, directed readings should not be taken under the supervision of a student's Senior Supervisor. We use directed readings sparingly but strategically in the program. Normally MA and MSc students may take at most one directed readings course for credit towards the degree. Normally PhD students may take at most two directed readings courses for credit towards the degree. Students may take at most one directed readings course with a given professor.

\section{Co-operative Education}

On an optional basis and with approval of the Graduate Program Committee, MA, MSc and $\mathrm{PhD}$ students may participate in co-operative education by placement in a government or private research agency to gain practical experience in their thesis or dissertation area. The co-operative education option is separate from coursework in the program and serves as an adjunct to the thesis/dissertation process.

The Research Colloquium is an important part of the scholarly life of the program. During their studies PhD students are required to present their research work in at least two seminars as part of this series. MA and MSc students are required to present in one seminar. There is an expectation of continuous participation. All students are expected to attend two-thirds of the seminars in the series while they are taking coursework in the program.

The $\mathrm{PhD}$ degree requires a comprehensive examination aimed at testing for achievement in interdisciplinarity, breadth of knowledge, depth of knowledge, topic focus and scholarly skill.

The $\mathrm{PhD}$ degree requires a dissertation proposal aimed at collegial review of the proposed work, development of research formulation and presentation skills and approval of the dissertation work by the Supervisory Committee and the Graduate Program Chair. The approval of the Graduate Program Chair is largely for oversight issues, for example, required ethics clearances. The dissertation proposal has two components: a research prospectus and a public event with timely notification given to the campus community.

The MA Thesis, MSc Thesis and PhD Dissertation are the formal vehicles by which students make the contribution to knowledge that is the hallmark of a research degree.

\section{RELATION TO CDEN}

The SIAT program (and others in Canada) represent design domains, forms of design education and significant design research that is only indirectly addressed by CDEN. Yet, the creation of any advanced product today integrates multiple design domains and requires expertise including, but extending well beyond, engineering design. While it is good to see many of the CDEN chairs engaging other design-oriented units at their universities, we argue that CDEN would benefit from being even more inclusive in its outlook. The benefits would include access to disciplines with mature, distinct and effective approaches to design education, the development of better communication and collaboration skills in engineering design students and more effective design outcomes that include the full range of disciplines required for successful design in a complex real world. For non-engineering design schools the benefits of engagement with CDEN include learning how to work with the highly effective and often focused culture of engineering and changes to design education to include more technology and greater understanding of the role of engineers and other professionals. Canadian society and its economy lie outside of all disciplinary bounds. There can be little doubt that producing graduates who can work effectively in the complex world of contemporary design would be for the greater good. Both engineering and other design disciplines can be proud of their accomplishments in this sphere, but it seems clear (to us at least) that much more can be done. 